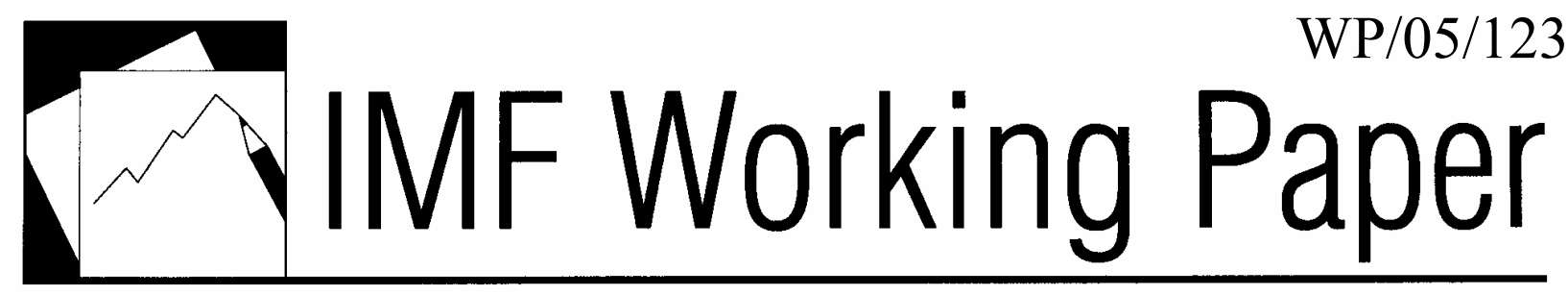

\title{
Endowment Versus Finance: \\ A Wooden Barrel Theory of International Trade
}

Jiandong Ju and Shang-Jin Wei 


\title{
IMF Working Paper
}

Research Department

\section{Endowment Versus Finance: A Wooden Barrel Theory of International Trade}

\author{
Prepared by Jiandong Ju and Shang-Jin Wei ${ }^{1}$
}

June 2005

\begin{abstract}
This Working Paper should not be reported as representing the views of the IMF. The views expressed in this Working Paper are those of the author(s) and do not necessarily represent those of the IMF or IMF policy. Working Papers describe research in progress by the author(s) and are published to elicit comments and to further debate.
\end{abstract}

This paper develops a theory of international trade in which financial development and factor endowments jointly determine comparative advantage. We apply the financial contract model of Holmstrom and Tirole (1998) to the Heckscher-Ohlin-Samuelson (HOS) model in which firms' dependence on external finance is endogenous, and the demand for external finance is constrained by financial development. The theory nests HOS model as a special case. A key result that emerges is what we call the law of a wooden barrel: if the external finance constraint is binding, then further financial development will increase the output of the industry more dependent on external finance, and decrease the output of the other industry. It is shown that financial development makes both labor and unemployed capital better off, but incumbent capital worse off. Therefore, financial development depends on the relative strength of political forces among labor, unemployed capital owners, and incumbent capital owners. If only the capital constraint is binding, on the other hand, the standard HOS predictions will apply.

JEL Classification Numbers: F11, G20

Keywords: External Finance, Factor Endowment, Financial Development, HOS model, Wooden Barrel

Author(s) E-Mail Address: jdju@ou.edu, swei@imf.org

\footnotetext{
${ }^{1}$ The authors are grateful to Eric Bond, Jim Cassing, Chitru Fernando, Haizhou Huang, Kala Krishna, Bill Megginson, Peter Neary, John Romalis, and Thierry Verdier for helpful discussions. All remaining errors are their own. Jiandong Ju is a professor at the University of Oklahoma. Shang-Jin Wei is Chief of the Trade and Investment Division in the Research Department of the International Monetary Fund and Director of the National Bureau of Economic Research's Working Group on the Chinese Economy (http://www.nber.org/ wei/).
} 


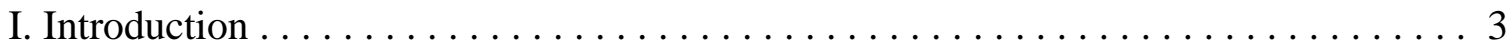

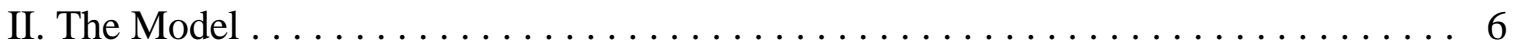

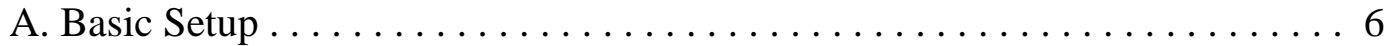

B. Dependence on External Finance $\ldots \ldots \ldots \ldots \ldots \ldots \ldots \ldots \ldots \ldots$

III. The Analysis: The Law of Wooden Barrel . . . . . . . . . . . . . . 11

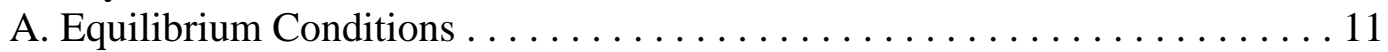

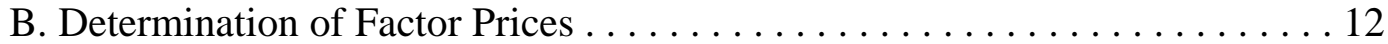

C. Comparative Statics . . . . . . . . . . . . . . . . . . . . 13

D. Conflict of Interests in Financial Development . . . . . . . . . . . 16

E. International Trade . . . . . . . . . . . . . . . . . . 17

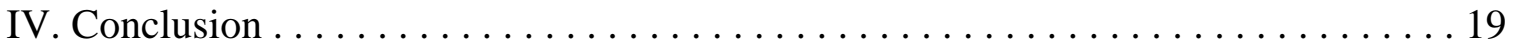

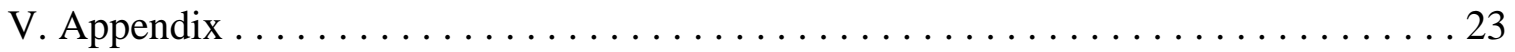


A wooden barrel may be formed with staffs of uneven length; How much water it can hold depends on its shortest staff - A Chinese proverb.

\section{INTRODUCTION}

Finland is relatively more abundant in forestry resources than Denmark. The classical Heckscher-Ohlin-Vanek (HOV) model of international trade would predict that Finland is more likely than Denmark to produce and export in resource intensive industries, such as wood products and furniture. Yet, as pointed out by Carlin and Mayer (2003), during recent decades, "the relative growth of these industries accelerated markedly in Denmark relative to Finland." The growth of four industries with the highest dependence on external finance in their study, instruments, electrical machinery, plastics and non-electrical machinery, increased during the 1980s and 1990s in Finland, but declined in Denmark. What may explain this apparent deviation from the HOV model? According to Carlin and Mayer, it is related to the fact that Finland is financially better developed. A formal regression analysis reveals that "measures of the financial structure of the two countries appear to be more relevant to the comparative performance of their industries than are the underlying resource endowments."

The Carlin and Mayer paper is part of a growing empirical literature, pioneered by Rajan and Zingales (1998) and followed by Beck and Levine (2002) and Fisman and Love (2004), among others, that demonstrates that, across many countries, those industries that rely relatively more on external capital are likely to grow faster relative to other industries in countries with a more developed financial system. In other words, cross-industry patterns of production and growth appear to be related to the nature of financial system, especially in terms of availability of capital external to firms. Perhaps it is not surprising that the effect of financial development should also show up in the trade data. Using a data set on 56 countries and 36 industries, Beck (2002) reports evidence that countries with higher levels of financial development have higher export shares and trade balances in industries that use more external finance.

These studies do not imply that factor endowment is irrelevant in explaining cross-country patterns of production and trade. Indeed, one sees in recent years a resurgence in papers reporting empirical support for the factor endowment based theory of international trade modified by allowing for technology differences across countries, including the influential works by Trefler (1993, 1995), Harrigan (1997), Davis and Weinstein (2001, 2003), and Romalis (2004).

These two sets of empirical papers suggest that both financial development and factor endowment are important in explaining patterns of production and trade. To our knowledge, there is no unifying theoretical model to this date that allows both elements simultaneously. In this paper, we aim to construct such a theory. Specifically, we apply the financial contract model of Holmstrom and Tirole (1998) to the Heckscher-Ohlin-Samuelson (HOS) framework, deriving firms' equilibrium internal-external capital structure, and then providing a general equilibrium theory of trade in which financial development plays a prominent role.

To preview some of the key results, our theory predicts a wooden barrel law of trade. When a 
country's financial system is underdeveloped (relative to the level of its capital endowment) so that capital owners are reluctant or not able to provide all the external capital that the entrepreneurs desire at the equilibrium interest rate, then the external finance constraint becomes binding - the shortest staff on the wooden barrel. The Rybczynski theorem no longer holds. An improvement in the financial system, however, would increase the output of the sector more dependent on external finance, and decrease the output of the other sector. Such an economy may be viewed as institution-binding: a failure in the capital market makes some capital unemployed. Increasing the supply of external finance by improving the financial institution would have a real effect on the economy. On the other hand, enlarging the size of capital endowment, e.g., through infusion of foreign cash grants, would have no effect on the economy.

When a country has a sufficiently developed financial system (relative to the size of its capital endowment), however, then all the standard results from the HOS model, such as the Rybczynski theorem, holds as in textbooks. In this case, capital endowment rather than external capital capacity is the binding constraint - the shortest staff on the wooden barrel. Such an economy may be labeled as endowment-binding: Enlarging the size of factor endowments would have a real effect on the economy, while improving the financial institution would have no effect. At different development stages, the economy could be mainly institution-binding or endowment-binding. Identifying which constraint is binding is a crucial question for public policy.

Like the standard trade theory, our theory predicts a conflict of interest between labor and capital. In addition, our theory predicts a conflict of interest between different owners of capital. When the external finance constraint is binding, a part of the capital endowment may be unemployed. On the one hand, financial development increases the relative output of the capital intensive industry, and therefore reduces its relative price. This decreases the return on capital and increases the wage rate. On the other hand, financial development relaxes the external finance constraint, and therefore reduces unemployment of capital. Both owners of unemployed capital and labor benefit from financial development, while owners of currently employed capital are worse off. In this sense, financial development depends on the relative strength of political forces among labor, unemployed (or potential) capital owners, and existing capital owners. Rajan and Zingales (2003) provided empirical support for a political economy theory of financial development. Our model, to the best of our knowledge, is the first one that provides a theoretical foundation for such a story.

Our model bears some resemblance to the three factors, two goods HOS model, but they are not the same thing. In the HOS model, product prices and factor prices together clear the product and factor markets. The financial system introduced in our model imposes an additional constraint which could result in the underemployment of capital in equilibrium.

Our theory may have important policy implications for economic development. When a financial system is deficient, for example, because of poor corporate governance, massive transfers of capital from abroad through the World Bank or the IMF, or cash grants from rich country governments, are unlikely to induce more productive investment. Policy priority should be on improving the financial institution and corporate governance rather than enlarging capital endowment. On the other hand, when the financial system is sufficiently developed, relaxing the constraint on the capital endowment would be useful, as predicted by the HOS model. 
For concreteness, consider Chile and Mexico, which had comparable per capita incomes in 1980. Both countries over the next two decades saw large scale capital inflows. Chile, however, appears to end up with a higher per capita income and better economic outcomes generally today, having avoided two financial crises along the way. The reasons behind the different performances are complex and myriad. We argue that the difference in the respective financial systems is one important factor. Chile has both a more developed stock market - measured by the ratio of stock market capitalization to GDP, and a more developed banking sector - measured by the ratio of domestic credit to private sector to GDP, than Mexico. ${ }^{2}$ Using the logic in our model, relaxing the constraint of capital stock such as through an inflow of international capital is more likely to generate productive investment in a country like Chile than in a country like Mexico.

This paper is related to the recent literature on international trade and organization of the firm. See McLaren (2000), Grossman and Helpman (2002, 2005), Levchenko (2003), and Costinot (2005) for applications of a transaction cost approach, and Antras (2003), Antras and Helpman (2004), and Nunn (2005) of a property rights approach. The existing literature applies the Grossman-Hart-Moore view of incomplete contracts in the study of organization of the firm, and focuses on the determinants of trade pattern by contract environment. In contrast, we apply the insights of Holmstrom and Tirole on moral hazard to study firms' dependence on external finance. As a result, our paper provides a way to understand how financial development and factor endowment jointly determine the trade pattern.

Our paper is also related to a small theoretical literature that models the role of financial system in determining production and trade patterns. Kletzer and Bardhan (1987), Baldwin (1989), Beck (2002), and Matsuyama (2005) show that countries with a relatively well-developed financial system have a comparative advantage in industries that rely more on financial system, while Do and Levchenko (2004) show that financial systems in countries with larger financially intensive sectors are more developed. These papers as well as our model provide a theoretical foundation for the Rajan-Zingales (1998) effect that has been robustly documented in a growing body of empirical studies. Our theory differs from these papers in three ways. First, none of the existing papers discusses the role of the financial system in an otherwise classic HOS-style trade model, whereas our model retains as much of the standard features as possible. Consequently, our model is the first in the literature that nests the HOS model as a special case. Second, unlike the existing papers, our paper considers the role of cross-country differences in financial system and in factor endowment simultaneously. Third, our model discusses the effect of the change in product prices on factor prices, which are building blocks for a future political economy analysis of financial development.

The rest of paper is organized as follows. Section II describes the setup of the model and discusses the microfoundation for firms' dependence on external finance. Section III analyzes the model with a set of key results including the wooden barrel theory. Section IV summarizes the result. Finally, an Appendix contains formal proofs of various propositions made in the text.

\footnotetext{
${ }^{2}$ The inference is based on Table 2, Rajan and Zingales (1998).
} 


\section{THE MODEL}

In an otherwise standard two goods, two factors, and two-countries HOS framework, we introduce firms' demand for liquidity. There is a large literature of multiperiod agency models in corporate finance in which long-term contract problems are solved to implement firms' second-best liquidity demand (see Diamond 1991, Berglof and von Thadden 1994, Hart and Moore 1998, and Holmstrom and Tirole 1998). We modify the setup in Holmstrom and Tirole (1998) from a one good, one factor model to a two goods, two factors model.

\section{A. Basic Setup}

Focusing now on a single country, we suppose that the production process takes two periods and the firm has a stochastic technology. The first period production function of industry $i$ is $y_{i}^{1}=$ $G_{i}\left(L_{i}, K_{i}^{1}\right), i=1,2$, where $y_{i}^{1}$ is the output produced using labor $L_{i}$ and date 1 investment $K_{i}^{1}$, if the project succeeds. The production functions are assumed to be homogeneous of degree one in $\left(L_{i}, K_{i}^{1}\right)$. The initial labor-capital ratio, $L_{i} / K_{i}^{1}$, is assumed to be fixed and denoted as $a_{i}^{1}$. Thus, $y_{i}^{1}=G_{i}\left(L_{i}, K_{i}^{1}\right)=G_{i}\left(a_{i}^{1}, 1\right) K_{i}^{1}$. Let $p_{i}$ be the price of good $i$ and $w$ be the wage rate. If the project succeeds, the capital revenue is

$$
p_{i} y_{i}^{1}-w L_{i}=\left[p_{i} G_{i}\left(a_{i}^{1}, 1\right)-w a_{i}^{1}\right] K_{i}^{1}=R_{i} K_{i}^{1}
$$

where $R_{i}=p_{i} G_{i}\left(a_{i}^{1}, 1\right)-w a_{i}^{1}$ represents the return to a unit of initial investment.

At the beginning of date 1 , a financial contract is signed between the firm and investors and an initial investment $K_{i}^{1}$ is injected to the firm. Correspondingly, $a_{i}^{1} K_{i}^{1}$ of labor are hired. The gain to capital is $R_{i} K_{i}^{1}$ if the project succeeds and zero if it fails. The labor is paid at $w$ in the second period. At the beginning of date 2 , an additional and uncertain amount $\rho_{i} K_{i}^{1}>0$ of financing is needed to cover operating expenditures and other needs. The liquidity shock $\rho_{i}$ is distributed according to the cumulative distribution function $F_{i}(\rho)$ with a density function $f_{i}(\rho)$. No labor is needed for liquidity shock. If $\rho_{i} K_{i}^{1}$ is paid, the project continues and the output of $G_{i}\left(a_{i}^{1}, 1\right) K_{i}^{1}$ will be produced at the end of date 2 . If $\rho_{i} K_{i}^{1}$ is not paid, the project terminates and produces nothing. The failed projects are liquidated and factors of these projects are reallocated at the beginning of the second period. Consumption takes place at the end of the second period. ${ }^{3}$

Investment is subject to moral hazard problem in the firm. The entrepreneur (firm) privately chooses an effort levels of either "work" or "shirk." If the entrepreneur works, the probability of success is $\lambda_{i}^{H}$ (high); if the entrepreneur shirks, the probability of success is $\lambda_{i}^{L}$ (low), where $\lambda_{i}^{H}-\lambda_{i}^{L}=\Delta \lambda_{i}>0$. If the entrepreneur shirks, the benefit to him is $B_{i} K_{i}^{1}>0$, which is proportional to the level of the investment $K_{i}^{1}$. The entrepreneur makes a decision on effort levels after the continuation decision is made in the second period.

At date 2, the first period investment $K_{i}^{1}$ is sunk. The net present value of the investment is maximized by continuing the project whenever the expected return from continuation, $\lambda_{i}^{H} R_{i}$,

\footnotetext{
${ }^{3}$ We combine three periods in the setup of Holmstrom and Tirole (1998) into two periods for simplicity.
} 
exceeds the cost $\rho_{i}$, that is, $\lambda^{H} R_{i}-\rho_{i} \geq 0$. Let

$$
\rho_{i}^{1}=\lambda_{i}^{H} R_{i}
$$

and refer it as the first-best cutoff and denote $r$ as the interest rate. Following Holmstrom and Tirole (1998), we assume that the project's net present value is positive if the entrepreneur works but not if he shirks. That is,

$$
\begin{aligned}
& \int \max \left[\lambda_{i}^{H} R_{i}-\rho_{i}, 0\right] f_{i}(\rho)-(1+r) \\
> & 0>\int \max \left[\lambda_{i}^{L} R_{i}+B-\rho_{i}, 0\right] f_{i}(\rho)-(1+r)
\end{aligned}
$$

Therefore, we only need to consider the contract implementing the effort of "work."

\section{B. Dependence on External Finance}

The empirical literature reports that the level of dependence on external finance across different industries varies dramatically. Rajan and Zingales (1998) define external finance as the amount of desired investment that cannot be financed through internal cash flows generated by the same business. They measure a firm's dependence on external finance by capital expenditures minus cash flow from operations divided by capital expenditures. ${ }^{4}$

Let the initial investment in the firm, $K_{i}^{1}=K_{i}^{N}+K_{i}^{X 1}$, where $K_{i}^{N}$ is firm's endowment of cash and $K_{i}^{X 1}$ is the funds that the firm raises from outside investors at date 1 . The firm has no endowment of cash at date 2 so the amount of internal capital is measured by $K_{i}^{N}$. The amount of external capital, $K_{i}^{X}$, is measured by $K_{i}^{X 1}$ plus the funds for additional liquidity shock $\rho_{i} K_{i}^{1}$ at date 2 .

Let $C_{i}=\left\{K_{i}^{1}, \mu_{i}\left(\rho_{i}\right), R_{i}^{B}\left(\rho_{i}\right)\right\}$ be the contract where $\mu_{i}\left(\rho_{i}\right)$ is a state-contingent continuation policy ( $1=$ continue, $0=$ stop), and $R_{i}^{B}\left(\rho_{i}\right)$ is the amount the entrepreneur is paid per unit of initial investment if the project succeeds. Investors are left with $R_{i}-R_{i}^{B}\left(\rho_{i}\right)$. If the project fails or is terminated, both sides are assumed to receive zero. Following Holmstrom and Tirole (1998), an optimal contract can be found by choosing $\left\{K_{i}^{1}, \mu_{i}\left(\rho_{i}\right), R_{i}^{B}\left(\rho_{i}\right)\right\}$ to solve the following moral hazard problem.

$$
\max U_{i}=K_{i}^{1} \int \lambda_{i}^{H} R_{i}^{B}\left(\rho_{i}\right) \mu_{i}\left(\rho_{i}\right) f_{i}\left(\rho_{i}\right) d \rho_{i}-(1+r) K_{i}^{N}
$$

subject to

$$
K_{i}^{1} \int\left\{\lambda_{i}^{H}\left[R_{i}-R_{i}^{B}\left(\rho_{i}\right)\right]-\rho_{i}\right\} \mu_{i}\left(\rho_{i}\right) f_{i}\left(\rho_{i}\right) d \rho_{i} \geq(1+r) K_{i}^{X 1}
$$

\footnotetext{
${ }^{4}$ Rajan and Zingales report that Drugs and Pharmaceuticals is the industry that uses the most external finance, having the external dependence ratio of 1.49. The external dependence ratio in Electric Machinery is 0.77 . Apparel, with the external dependence ratio of 0.03 , has little external funding needs.
} 
and

$$
R_{i}^{B}\left(\rho_{i}\right) \lambda_{i}^{H} \geq R_{i}^{B}\left(\rho_{i}\right) \lambda_{i}^{L}+B_{i}
$$

The expression (4) is the firm's net return. (5) is the participating constraint of investors, while (6) is the entrepreneur's incentive compatibility constraint. Solving the above problem, the optimal continuation policy $\mu_{i}\left(\widehat{\rho}_{i}\right)$ is a cutoff rule that $\mu_{i}\left(\widehat{\rho}_{i}\right)=1$ if $\rho_{i} \leq \widehat{\rho}_{i}$ and $\mu_{i}\left(\widehat{\rho}_{i}\right)=0$ if $\rho_{i}>\widehat{\rho}_{i}$. Let $\rho_{i}^{0}=\lambda_{i}^{H}\left[R_{i}-R_{i}^{B}\left(\rho_{i}\right)\right]$ and rewrite the expression (5) as $K_{i}^{N} \geq K_{i}^{1} / n_{i}\left(\widehat{\rho}_{i}\right)$, where

$$
n_{i}\left(\widehat{\rho}_{i}\right)=\frac{1+r}{(1+r)-\int_{0}^{\widehat{\rho}_{i}}\left(\rho_{i}^{0}-\rho_{i}\right) f_{i}\left(\rho_{i}\right) d \rho_{i}}
$$

represents the equity multiplier, which is quasi-concave in $\widehat{\rho}_{i}$ and maximized at $\widehat{\rho}_{i}=\rho_{i}^{0}$. If $\frac{1}{n_{i}\left(\widehat{\rho}_{i}\right)} \leq 0$, the investors' expected marginal return on their investment at date 1 would be larger than the opportunity cost. The firm would be free to invest arbitrarily large amounts at date 1 , making the moral hazard problem unconstrained. Following Holmstrom and Tirole (1998), we assume

$$
\int_{0}^{\widehat{\rho}_{i}}\left(\rho_{i}^{0}-\rho_{i}\right) f_{i}\left(\rho_{i}\right) d \rho_{i}<1+r
$$

to eliminate this case. The condition (8) is necessary and sufficient for the participating constraint (5) to be binding, which gives the firm's initial investment

$$
K_{i}^{1}=K_{i}^{1}\left(\widehat{\rho}_{i}\right)=n_{i}\left(\widehat{\rho}_{i}\right) K_{i}^{N}
$$

Substituting binding constraint (5) into (4), the firm's objective function can be written as $U_{i}\left(\widehat{\rho}_{i}\right)=m_{i}\left(\widehat{\rho}_{i}\right) K_{i}^{1}$, where

$$
m_{i}\left(\widehat{\rho}_{i}\right)=\int_{0}^{\widehat{\rho}_{i}}\left(\rho_{i}^{1}-\rho_{i}\right) f_{i}\left(\rho_{i}\right) d \rho_{i}-(1+r)
$$

is the marginal net social return on investment. $m_{i}\left(\widehat{\rho}_{i}\right)$ is quasi-concave and maximized at $\widehat{\rho}_{i}=\rho_{i}^{1}$. Condition (3) ensures that $m_{i}\left(\rho_{i}^{1}\right)>0$. Note that $\widehat{\rho}_{i}=\rho_{i}^{1}$ is feasible for the moral hazard problem. Thus, at the optimal contract $\widehat{\rho}_{i}=\rho_{i}^{*}$, we must have $U_{i}\left(\rho_{i}^{*}\right)=m_{i}\left(\rho_{i}^{*}\right) K_{i}^{1}\left(\rho_{i}^{*}\right) \geq m_{i}\left(\rho_{i}^{1}\right) K_{i}\left(\rho_{i}^{1}\right)>0$. Given $m_{i}\left(\rho_{i}^{*}\right)>0$, the firm will choose $R_{i}^{B}\left(\rho_{i}\right)$ as small as possible to maximize $K_{i}^{1}\left(\rho_{i}^{*}\right)$. Thus, the incentive compatibility constraint (6) must be binding, which gives

$$
R_{i}^{B}=\frac{B_{i}}{\Delta \lambda_{i}} \text { and } \rho_{i}^{0}=\lambda_{i}^{H}\left[R_{i}-\frac{B_{i}}{\Delta \lambda_{i}}\right]
$$

Using (7), (9), and (10), the firm's net return becomes

$$
U_{i}\left(\widehat{\rho}_{i}\right)=m_{i}\left(\widehat{\rho}_{i}\right) n_{i}\left(\widehat{\rho}_{i}\right) K_{i}^{N}=\frac{(1+r)\left[\rho_{i}^{1}-h\left(\widehat{\rho}_{i}\right)\right]}{h\left(\widehat{\rho}_{i}\right)-\rho_{i}^{0}} K_{i}^{N}
$$

where

$$
h\left(\widehat{\rho}_{i}\right)=\frac{(1+r)+\int_{0}^{\widehat{\rho}_{i}} \rho_{i} f_{i}\left(\rho_{i}\right) d \rho_{i}}{F_{i}\left(\widehat{\rho}_{i}\right)}
$$


Because $m_{i}\left(\widehat{\rho}_{i}\right)$ and $n_{i}\left(\widehat{\rho}_{i}\right)$ are both concave, we must have $\rho_{i}^{0}<\rho_{i}^{*}<\rho_{i}^{1} . h\left(\widehat{\rho}_{i}\right)$ represents the virtual cost of the unit investment, which is the opportunity cost of initial investment at date 1 , $(1+r)$, plus the expected financing for the liquidity shock at date $2, \int_{0}^{\widehat{\rho}_{i}} \rho_{i} f_{i}\left(\rho_{i}\right) d \rho_{i}$, under the condition that the project continues. Maximizing $U_{i}\left(\widehat{\rho}_{i}\right)$ is equivalent to minimizing $h\left(\widehat{\rho}_{i}\right)$. The first order condition then gives

$$
\int_{0}^{\rho_{i}^{*}} F_{i}\left(\rho_{i}\right) d \rho_{i}=1+r
$$

which implies that $h\left(\rho_{i}^{*}\right)=\rho_{i}^{*}$. The firm's net return with optimal contract can now be written as $U_{i}\left(\rho_{i}^{*}\right)=R_{i}^{N} K_{i}^{N}$, where

$$
R_{i}^{N}=\frac{(1+r)\left[\rho_{i}^{1}-\rho_{i}^{*}\right]}{\rho_{i}^{*}-\rho_{i}^{0}}
$$

represents the firm's marginal net return on internal capital.

Equation (14) shows that optimal cutoff of the liquidity shock, $\rho_{i}^{*}$, increases as $r$ increases. As the interest rate $r$ becomes higher, the opportunity cost of the investment is higher. To attract investors into the project, the firm needs to promise higher probability that the project continues under the liquidity shock, which implies higher optimal cutoff rate $\rho_{i}^{*}$. We summarize this result as the following Lemma, which will become useful for analysis in later sections.

Lemma 1 The optimal cutoff of the liquidity shock, $\rho_{i}^{*}$, increases as the interest rate $r$ increases.

We now are ready to derive the firm's dependence on external finance. Let there be a continuum of firms in industry $i$ with unit mass. Each firm is endowed with $K_{i}^{N}$ units of internal capital. Liquidity shocks $\rho_{i}$ for each firm are independent. Thus, $F_{i}\left(\rho_{i}\right)$ denotes both the ex ante probability of a firm facing a liquidity shock below $\rho_{i}$ and the realized fraction of firms with liquidity shock below $\rho_{i}$. The total capital usage is the sum of initial investment $K_{i}^{1}\left(\rho_{i}^{*}\right)$ and expected liquidity shocks being paid. Denoting the total capital usage as $K_{i}$, we have

$$
\begin{aligned}
K_{i} & =\left[(1+r)+\int_{0}^{\rho_{i}^{*}} \rho_{i} f_{i}\left(\rho_{i}\right) d \rho_{i}\right] K_{i}^{1}\left(\rho_{i}^{*}\right) \\
& =\left[(1+r)+\int_{0}^{\rho_{i}^{*}} \rho_{i} f_{i}\left(\rho_{i}\right) d \rho_{i}\right] n_{i}\left(\rho_{i}^{*}\right) K_{i}^{N} \\
& =s_{i}\left(\rho_{i}^{*}\right) K_{i}^{N}
\end{aligned}
$$

where

$$
s_{i}\left(\rho_{i}^{*}\right)=\frac{(1+r)\left(1+r+\int_{0}^{\rho_{i}^{*}} \rho_{i} f_{i}\left(\rho_{i}\right) d \rho_{i}\right)}{(1+r)-\int_{0}^{\rho_{i}^{*}}\left(\rho_{i}^{0}-\rho_{i}\right) f_{i}\left(\rho_{i}\right) d \rho_{i}}
$$

The labor-capital ratio in the entire production process becomes

$$
\begin{aligned}
a_{i}\left(\rho_{i}^{*}\right) & =\frac{L_{i}}{K_{i}}=\frac{1}{1+r+\int_{0}^{\rho_{i}^{*}} \rho_{i} f_{i}\left(\rho_{i}\right) d \rho_{i}}\left(\frac{L_{i}}{K_{i}^{1}\left(\rho_{i}^{*}\right)}\right) \\
& =\frac{a_{i}^{1}}{1+r+\int_{0}^{\rho_{i}^{*}} \rho_{i} f_{i}\left(\rho_{i}\right) d \rho_{i}}
\end{aligned}
$$


The external dependence index, which is measured by external capital to total capital ratio, is equal to

$$
\phi_{i}=\frac{K_{i}-K_{i}^{N}}{K_{i}}=\frac{s_{i}\left(\rho_{i}^{*}\right)-1}{s_{i}\left(\rho_{i}^{*}\right)}
$$

The firm's expected output (realized industry output) is

$$
y_{i}=F_{i}\left(\rho_{i}^{*}\right) \lambda_{i}^{H} G_{i}\left(a_{i}^{1}, 1\right) K_{i}^{1}\left(\rho_{i}^{*}\right)=F_{i}\left(\rho_{i}^{*}\right) \lambda_{i}^{H} G_{i}\left(a_{i}^{1}, 1\right) n_{i}\left(\rho_{i}^{*}\right) K_{i}^{N}
$$

We will assume that $f_{i}\left(\rho_{i}\right)$ is a uniform distribution in $\left[0, \overline{\rho_{i}}\right]$. The expression (14) gives the solution of $\rho_{i}^{*}$ as

$$
\rho_{i}^{*}=\left[2(1+r) \overline{\rho_{i}}\right]^{\frac{1}{2}}
$$

Using equations (18) and (21), the labor intensity (labor-capital ratio) in the entire production process is

$$
a_{i}\left(\rho_{i}^{*}\right)=a_{i}(r)=\frac{a_{i}^{1}}{2(1+r)}
$$

The initial labor-capital ratio, $a_{i}^{1}$, is assumed to be fixed. As Lemma 1 shows, more capital will be injected as the interest rate $r$ increases. Thus, the labor intensity $a_{i}\left(\rho_{i}^{*}\right)$ decreases as interest rate increases. However, if we had allowed $a_{i}^{1}$ to be a function of $(w, r), a_{i}^{1}(w, r)$ would have increased as $r$ increased, since the firm would have liked to use more labor if the capital had become more expensive, and the overall labor intensity $a_{i}\left(\rho_{i}^{*}\right)$ may or may not have decreased as the interest rate had increased. 


\section{The Analysis: The LAW OF WOOden BarRel}

We will first derive equilibrium conditions in both factor and product markets and then follow the standard procedure in the theory of international trade to analyze the model. An external finance constraint-the sum of external capital usages across all industries does not exceed the external capital capacity in the country-is added to labor and capital constraints. Note that in determining equilibrium outputs $\left(y_{1}^{*}, y_{2}^{*}\right)$, these three constraints cannot be all binding. This is where the law of wooden barrel comes from: only two binding constraints out of three-the shortest staffs of the wooden barrel-determine the equilibrium outputs.

\section{A. Equilibrium Conditions}

The first set of equilibrium conditions for the two-by-two economy is that firm's marginal net return on internal capital should equal its opportunity cost. Let there be $K_{i}^{N}$ of entrepreneurs in sector $i$ and each of them is endowed with one unit of capital. We assume that capital owners need to pay a unit cost of $f$ at the beginning of the first period to become the entrepreneur. $f$ may represent the cost of training or the fee of certification. Using equation (15), the conditions are stated as

$$
\begin{aligned}
& R_{1}^{N}\left(p_{1}, w, r\right)=\frac{(1+r)\left[\rho_{1}^{1}-\rho_{1}^{*}\right]}{\rho_{1}^{*}-\rho_{1}^{0}}=(1+r) f \\
& R_{2}^{N}\left(p_{2}, w, r\right)=\frac{(1+r)\left[\rho_{2}^{1}-\rho_{2}^{*}\right]}{\rho_{2}^{*}-\rho_{2}^{0}}=(1+r) f
\end{aligned}
$$

which are called internal capital net return curves.

The second set of equilibrium conditions is factor endowment constraints. Using equations (16) and (20), we have

$$
K_{i}=b_{i}(r) y_{i}
$$

where

$$
b_{i}(r)=\frac{s_{i}\left(\rho_{i}^{*}\right)}{F_{i}\left(\rho_{i}^{*}\right) \lambda_{i}^{H} G_{i}\left(a_{i}^{1}, 1\right) n_{i}\left(\rho_{i}^{*}\right)}=\frac{[2(1+r)]^{\frac{1}{2}}}{G_{i}\left(a_{i}^{1}, 1\right)}\left(\frac{{\frac{\rho_{i}}{2}}^{\frac{1}{2}}}{\lambda_{i}^{H}}\right)
$$

is the capital usage per unit of good $i$ in the entire production process. Note that $b_{i}(r)$ is only a function of $r$ in our model. The capital usage per unit of good $i$ at date $1, \frac{1}{G_{i}\left(a_{i}^{1}, 1\right)}$, is adjusted by the probability of success and the liquidity shock at date 2 , which is represented by the multiplier $\beta_{i}=\frac{\bar{\rho}_{i}^{\frac{1}{2}}}{\lambda_{i}^{H}}$. Let $L$ and $K$ be the country's labor and capital endowments, respectively. The factor endowment constraints are written as

$$
\begin{aligned}
a_{1}(r) b_{1}(r) y_{1}+a_{2}(r) b_{2}(r) y_{2} & \leq L \\
b_{1}(r) y_{1}+b_{2}(r) y_{2} & \leq K
\end{aligned}
$$


The sector 1 is labor intensive if $a_{1}(r)>a_{2}(r)$, which is equivalent to $a_{1}^{1}>a_{2}^{1}$ in our model. We denote $\widetilde{a}_{i}=\frac{a_{i}^{1}}{\beta_{i}}=\frac{\lambda_{i}^{H} a_{i}^{1}}{\bar{\rho}_{i}^{\frac{1}{2}}}$ and call it effective labor intensity, which will be used in later sections.

The third set of equilibrium conditions is the external finance constraint, which requires that the sum of external capital usages across all industries cannot exceed the external capital capacity in the country. Let the country's external capital capacity be $K^{X}$. The external finance constraint is stated as

$$
\phi_{1}\left(p_{1}, w, r\right) b_{1}(r) y_{1}+\phi_{2}\left(p_{1}, w, r\right) b_{2}(r) y_{2} \leq K^{X}
$$

Higher external capital capacity to GDP ratio represents a more developed financial system. In empirical literature, stock market capitalization, domestic credit to private sector, and stock market capitalization plus domestic credit have all been used to measure $K^{X}$. Countries at similar levels of economic development differ dramatically in their levels of financial development. La Porta et al. (1997, 1998) show that the country's financial development is determined by the legal protection of investors. Common-law countries generally have both the strongest investor protection and the most developed capital market, whereas the French-civil-law countries possess the weakest investor protection and the least developed capital market. Rajan and Zingales (2003) argue that the strength of political forces in favor of financial development is a major variable factor, and incumbents in sectors of finance and industry may oppose financial development since it breeds competition. How the country's $K^{X}$ is determined is a matter beyond the scope of this paper. We will treat $K^{X}$ as an exogenous variable and analyze the effect of its increase on equilibrium outputs and prices.

The fourth equilibrium condition requires that the product market clears. We assume that the representative consumer's preference is homothetic. Thus, the ratio of the quantities consumed, $D\left(\frac{p_{1}}{p_{2}}\right)$, depends only upon the relative commodity price ratio. Let relative supply equal relative demand. The condition that the product market clears is stated as

$$
\frac{y_{1}}{y_{2}}=D\left(\frac{p_{1}}{p_{2}}\right)
$$

\section{B. Determination of Factor Prices}

Following the standard procedure in the theory of international trade (Feenstra 2004), we first solve for equilibrium factor prices $(w, r)$ under given product prices $\left(p_{1}, p_{2}\right)$. Substituting equations (2), (11) and (21) into (23), internal capital net return curves can be written as

$$
\begin{aligned}
& \lambda_{1}^{H} a_{1}^{1} w+\left[2(1+r) \overline{\rho_{1}}\right]^{\frac{1}{2}}=\lambda_{1}^{H}\left[p_{1} G_{1}\left(a_{1}^{1}, 1\right)-\left(\frac{f}{1+f}\right) R_{1}^{B}\right] \\
& \lambda_{2}^{H} a_{2}^{1} w+\left[2(1+r) \overline{\rho_{2}}\right]^{\frac{1}{2}}=\lambda_{2}^{H}\left[p_{2} G_{2}\left(a_{2}^{1}, 1\right)-\left(\frac{f}{1+f}\right) R_{2}^{B}\right]
\end{aligned}
$$


It is easy to show that internal capital net return curves are convex towards origin and downward sloping in $(w, r)$ space. The slopes of internal capital net return curves are

$$
\frac{d r}{d w}=-\frac{[2(1+r)]^{\frac{1}{2}} \lambda_{i}^{H} a_{i}^{1}}{\bar{\rho}_{i}^{\frac{1}{2}}}=-[2(1+r)]^{\frac{1}{2}} \widetilde{a}_{i} \text { for } i=1,2
$$

where $\widetilde{a}_{i}=\left(\lambda_{i}^{H} a_{i}^{1}\right) / \bar{\rho}_{i} \frac{1}{2}$, is the effective labor intensity defined in Section III A. Assume that $\widetilde{a}_{1}>\widetilde{a}_{2}$, so sector 1 is effectively labor intensive than sector 2 . As indicated in Figure 1 , the internal capital net return curve of sector 1 is steeper than that of sector 2 . The result similar to Stolper-Samuelson theorem holds here. The initial factor price equilibrium is given by point $A$. An increase in the price of good 1 will shift out the internal capital net return curve of sector 1 , as illustrated, and move the equilibrium to point $B$. It is clear that the wage has gone up, from $w_{0}$ to $w_{1}$, and the interest rate has declined, from $r_{0}$ to $r_{1}$.

Proposition 1 An increase in the price of a good will increase the return to the factor used intensively (effectively) in that good, and reduce the return to the other factor.

\section{Comparative Statics}

The labor constraint (26), the capital constraint (27), and the external finance constraint (28) will jointly determine the equilibrium outputs $\left(y_{1}^{*}, y_{2}^{*}\right)$. They are denoted by the $L L, K K$, and $X X$ lines in Figure 2, respectively. Industry 1 is labor intensive so that the $L L$ line is steeper than the $K K$ line. If the labor-intensive industry is less dependent on external finance than the capital-intensive industry, i.e., $\phi_{1}<\phi_{2}$, the $X X$ line will be flatter than the $K K$ line. Otherwise the $X X$ line will be steeper than the $K K$ line. The intersection between the $L L$ and $K K$ lines is denoted as point $E$ in Figure 2. If the $X X$ line crosses the point $E$, the external finance constraint is exactly binding in which the country's external capital capacity exactly meets the demand for external finance from all industries when factors are fully employed. If the $X X$ line is outside the point $E$, the external finance constraint is non-binding. The country's financial system in this case is defined as developed relative to the level of factor endowments: the country's external capital capacity exceeds the demand for external finance from all industries when factors are fully employed. If the $X X$ line is inside the point $E$, the external finance constraint is binding and the country's financial system is underdeveloped relative to the level of factor endowments: the country's external capital capacity cannot meet the demand for external finance at the equilibrium interest rate. The case of an exactly binding is a knife-edge. For comparative statics, we consider cases when the external finance constraint is binding or non-binding.

The level of external finance is described by a technology coefficient, $\phi_{i}$, and a capacity parameter, $K^{X}$. We will assume for simplicity that financial development increases external finance capacity $K^{X}$, but has no effect on technology $\phi_{i}$.

We first study the case of the non-binding external finance constraint, which we denote as Case 1 and depict in Figure 2. The equilibrium output $E$ is determined by the intersection of the $L L$ and the $K K$ lines, while the $X X$ line is outside point $E$. Consider first an improvement in the 
financial system such that the $X X$ line shifts out to the $X^{\prime} X^{\prime}$, while the $L L$ and $K K$ lines do not change. It can be immediately seen that such an improvement has no effect on the equilibrium output $E$. The financial system is able to provide up to $K^{X}$ of external capital. The equilibrium amount of external capital, however, is determined by the demand for external capital at interest rate $r$, which is equal to $\phi_{1} b_{1} y_{1}^{*}+\phi_{2} b_{2} y_{2}^{*}$ and less than the external capital capacity. The country's financial system is not a constraint. Factor endowments determine the economic outcome. If the capital endowment is augmented, say, by an infusion of an international cash grant, the financial system is capable of turning the cash grant into effective investment and raise the country's output.

The comparative statics in this case is actually reduced to the classic Rybczynski theorem. Rewrite the binding factor constraints (26) and (27) as

$$
\begin{aligned}
a_{1 L} y_{1}+a_{2 L} y_{2} & =L \\
a_{1 K} y_{1}+a_{2 K} y_{2} & =K
\end{aligned}
$$

where $a_{i L}=a_{i}(r) b_{i}\left(p_{i}, w, r\right)$ and $a_{i K}=b_{i}\left(p_{i}, w, r\right)$. Totally differentiating these equations and using the "Jones' algebra," we obtain

$$
\begin{aligned}
\lambda_{1 L} \widehat{y}_{1}+\lambda_{2 L} \widehat{y}_{2} & =\widehat{L}-\left[\lambda_{1 L} \widehat{a}_{1 L}+\lambda_{2 L} \widehat{a}_{2 L}\right] \\
\lambda_{1 K} \widehat{y}_{1}+\lambda_{2 K} \widehat{y}_{2} & =\widehat{K}-\left[\lambda_{1 K} \widehat{a}_{1 K}+\lambda_{2 K} \widehat{a}_{2 K}\right]
\end{aligned}
$$

We define $d y_{1} / y_{1}=\widehat{y}_{1}$, and likewise for all other variables. In addition, we define the fraction of labor used in industry $i, \lambda_{i L}=y_{i} a_{i L} / L$, where $\lambda_{1 L}+\lambda_{2 L}=1$. We define $\lambda_{i K}$ in analogous manner. $\widehat{L}$ and $\widehat{K}$ represent the direct effect of changes in endowments at given product prices, while the second terms in the right hand side of equations (34) represent the feedback effect of induced product price changes on the factor usage per unit of production. As shown in the Appendix, we obtain the classical magnification effect that $\widehat{y}_{1}^{T}>\widehat{L}>\widehat{K}>\widehat{y}_{2}^{T}$, when we consider the direct effect. As depicted in Figure 2, the initial equilibrium output is given by point $E$. An increase in the labor endowment shifts $L L$ out to $L^{\prime} L^{\prime}$ and moves the equilibrium to point $E^{\prime}$. It is clear that the output of good 1 goes up, whereas the output of good 2 declines.

As $y_{1}$ is increased while $y_{2}$ is reduced, equation (29) indicates that $p_{1}$ decreases relative to $p_{2}$ in the equilibrium. By Proposition 1, $r$ increases while $w$ decreases. As discussed at the end of the last section, more capital would be injected to the project and $a_{i}(r)$ decreases as $r$ increases. Note that the feedback effect is somewhat different from the classical HOS model. Labor usage per unit of production decreases, while capital usage per unit of production increases. Thus, the feedback effect shifts the $L^{\prime} L^{\prime}$ line out further to $L^{\prime \prime} L^{\prime \prime}$ and shifts the $K K$ line in to $K^{\prime \prime} K^{\prime \prime}$, which moves the equilibrium from $E^{\prime}$ further down to $E^{\prime \prime}$. The feedback effect strengthens rather than dampens the magnification effect, increasing $y_{1}$ and reducing $y_{2}$ further. As we discussed at the end of the last section, if $a_{i}^{1}$ were allowed to change, we could have the classical feedback effect which would dampen the magnification effect. However, as long as the stability condition holds, the magnification effect is more than compensated for the dampening effect of price changes, so that the Rybczynski theorem always holds. An increase in $K$ can be similarly analyzed. We now summarize our results by the following proposition. 
Proposition 2 If the financial system is sufficiently developed, the equilibrium output is determined by the factor endowment constraints. Further financial development has no effect on the equilibrium outcome. An increase in a factor endowment will increase the output of the industry that uses it intensively, and decrease the output of the other industry.

We now turn to cases of binding external finance constraint. We assume that the capital-intensive industry is more dependent on external finance, i.e., $\phi_{2}>\phi_{1}$. This is denoted as Case 2 and depicted in Figure 3. The $X X$ line is inside point $E$ and flatter than the $K K$ line. It must be the case that the $L L$ and $X X$ lines are binding, while the $K K$ line is not binding. Equilibrium outputs $\left(y_{1}^{*}, y_{2}^{*}\right)$ are determined by the labor constraint (26) and the external finance constraint (28), as indicated by point $A$. The actual capital usage is $K^{*}=b_{1} y_{1}^{*}+b_{2} y_{2}^{*}<K$. The unemployment of capital is denoted as $K^{U}$, which is equal to $K-K^{*}$, and measured by $A E$.

$K$ is the total amount of capital that could be used in production if the financial system were sufficiently developed. If the financial system is underdeveloped, however, some of capital may be unemployed: even though firms may wish to have more external capital, capital owners (households with savings) are reluctant to invest all their capital in the firms due to moral-hazard induced failure of capital market.

To use more capital, firms would like to produce more capital-intensive goods relative to labor-intensive goods, which would require more external capital. However, the binding external finance constraint prevents any capital usage beyond $K^{*}$. An increase in capital endowment would only raise $K^{U}$ and have no effect on the equilibrium outcome.

Rewrite the binding labor constraint (26) and financial development constraint (28) as

$$
\begin{aligned}
a_{1 L} y_{1}+a_{2 L} y_{2} & =L \\
a_{1 X} y_{1}+a_{2 X} y_{2} & =K^{X}
\end{aligned}
$$

where $a_{i X}=\phi_{i}\left(p_{i}, w, r\right) b_{i}\left(p_{i}, w, r\right)$ is the external capital usage per unit of production. Totally differentiating these conditions and using "Jones' algebra," we obtain

$$
\begin{aligned}
\lambda_{1 L} \widehat{y}_{1}+\lambda_{2 L} \widehat{y}_{2} & =\widehat{L}-\left[\lambda_{1 L} \widehat{a}_{1 L}+\lambda_{2 L} \widehat{a}_{2 L}\right] \\
\lambda_{1 X} \widehat{y}_{1}+\lambda_{2 X} \widehat{y}_{2} & =\widehat{K^{X}}-\left[\lambda_{1 X} \widehat{a}_{1 X}+\lambda_{2 X} \widehat{a}_{2 X}\right]
\end{aligned}
$$

Define the fraction of external capital used in industry $i, \lambda_{i X}=y_{i} a_{i X} / K^{X}$, where $\lambda_{1 X}+\lambda_{2 X}=1$. Similar to Case 1, we obtain the magnification effect that $\widehat{y}_{2}>\widehat{K^{X}}>\widehat{L}>\widehat{y}_{1}$ when the direct effect is considered. The direct effect of financial development on equilibrium outputs is also depicted in Figure 3. A financial development shifts the $X X$ line out to the $X^{\prime} X^{\prime}$ line, as illustrated, moving the equilibrium from point $A$ to point $A^{\prime}$. It is clear that the output of industry 2 , the industry more dependent on external finance, goes up, and the output of industry 1 declines.

We then consider the feedback effect. The increase in $y_{2}$ and the decrease in $y_{1}$ raise equilibrium price $p_{1}$ relative to $p_{2}$, which reduces $r$ by Proposition 1. As we argued before, the decrease in $r$ 
raises labor usage per unit of production, while reducing external capital usage per unit of production. Thus, the feedback effect shifts in $L L$ to $L^{\prime \prime} L^{\prime \prime}$ and shifts out $X^{\prime} X^{\prime}$ further to $X^{\prime \prime} X^{\prime \prime}$, which moves the equilibrium from $A^{\prime}$ further up to $A^{\prime \prime}$. Again, the feedback effect strengthens rather than dampens the magnification effect, increasing $y_{2}$ and reducing $y_{1}$ further.

Case 3-that the labor intensive industry is more dependent on external finance-seems counter intuitive, ${ }^{5}$ while all our analysis above goes through as well. Further financial development increases the output of industry 1 , the industry more dependent on external finance, while reducing the output of industry 2 . The analysis and the proof of this case is relegated to the Appendix. We summarize our results for cases of binding external finance constraint as the following proposition.

Proposition 3 Suppose the financial system is underdeveloped, then the equilibrium outputs are determined by the external finance constraint and the binding factor endowment constraint. There can be unemployment of some factor in equilibrium. An increase in the endowment of the non-binding factor has no effect on the economy. A further financial development will increase the output of the industry more dependent on external finance, and decrease the output of the other industry.

It is worth noting that our comparative statics bears some resemblance to a three factors, two goods HOS model, but they are not the same thing. More factors than goods in the standard HOS model makes the Rybczynski theorem no longer hold. However, it does not create a non-binding constraint and unemployment of factors. In the three factors, two goods HOS model, six endogenous variables (one relative product price, three factor prices, and two outputs) need to be determined by the general equilibrium system. A product market clearing condition like (29), two zero profit conditions, and three full employment conditions like (33) would exactly solve for six endogenous variables. Product prices and factor prices together are able to clear product and factor markets in the standard general equilibrium analysis. It is the institutional constraint introduced in our model that imposes an additional constraint to the general equilibrium analysis, which results in problems of non-binding constraint and unemployment of factors. Intuitively, it is failure of capital market due to poor financial institution, rather than more factors than goods, that causes unemployment of resources.

\section{Conflict of Interests in Financial Development}

Not all factors benefit from financial development. In Figure 3 a further financial development represented by the increase in $K^{X}$ raises $y_{2}$ and reduces $y_{1}$ and moves the equilibrium from point $A$ to point $A^{\prime \prime}$. It is immediately seen that the unemployment of capital $K^{U}$ is reduced from $A E$ to $A^{\prime \prime} H$. A better financial system allows more capital endowment to be employed. The increase in $y_{2}$ and the decrease in $y_{1}$ raise equilibrium price $p_{1}$ relative to $p_{2}$, which raises $w$ and reduces $r$

\footnotetext{
${ }^{5}$ There is some empirical evidence to support Case 3. As Rajan and Zingales (1998) documented, Textile, a traditional labor-intensive industry, has an external dependence ratio of 0.40 , which is much higher than the external dependence ratio of a traditional capital-intensive industry Iron and Steel, 0.09.
} 
by Proposition 1. Therefore, financial development makes unemployed capital better off, all labor better off, but the currently employed capital worse off. A more developed financial system facilitates entry, and thus benefits the unemployed capital; however it makes the capital market more competitive, and thus leads to lower return for incumbent capital owners.

Proposition 4 In a country with an underdeveloped financial system, further financial development makes owners of unemployed capital better off, all labor better off, but owners of incumbent capital worse off.

As Rajan and Zingales (2003) mentioned, "financial development is so beneficial that it seems strange that anyone would oppose it." Nevertheless, their empirical investigation supports an interest group theory of financial development where incumbents oppose financial development because it breeds competition. Our analysis above provides a possible theoretical foundation for a political economy theory of financial development. In our model, labor and unemployed capital owners support, while incumbent capital owners oppose financial development. The country's financial development will be determined by the strength of political forces among these different interest groups.

\section{E. International Trade}

The financial system, in addition to factor endowments, determines patterns of trade. Consider two countries with binding external finance constraints, identical technologies, identical liquidity shocks and managers' behavior, identical and homothetic tastes, and identical factor endowments. They engage in free trade in goods (but not factors). We will assume away the possibility of factor intensity reversals. We assume that the home country has a more developed financial system than the foreign country so that $K^{X}>K^{X *}{ }^{6}$

Let us begin with the autarky equilibria. From Proposition 3, home must produce relatively more of the financially dependent good. Let $p^{a}$ be the autarky relative price of that good at home. The foreign autarky relative price must be higher than that at home. That is, $p^{a *}>p^{a}$. Let $p$ be the relative price in a free trade equilibrium. Similar to the arguments of the textbook HOS model, we must have $p^{a}<p<p^{a *}$. Thus, home exports the good produced by the more financially dependent industry, and imports the good produced by the less financially dependent industry. Provided that all countries have their endowments and external capital capacity within their "cone of diversification," factor prices in each country are uniquely determined by product prices, using equations (30) and (31). That is, factor prices are equalized across countries. The country as a whole gains from free trade, since the representative consumer reaches higher utility than in autarky. At home, the factor used intensively in the industry more dependent on external finance will gain from opening of the trade, while the other factor loses. The reverse is true in the foreign country.

\footnotetext{
${ }^{6}$ The superscript $*$ is used to denote variables in the foreign country.
} 
Proposition 5 Suppose the external finance constraints in both countries are binding. The country with a more developed financial system exports the good that is relatively more dependent on external finance in the production process.

Following the standard HOS model, we do not consider capital movement across countries. In the case discussed above, capital prices are equalized in the two countries so that employed capital will not move across countries. Unemployed capital will not move either, since the capital usage in each country has already reached its limit bound by external capital capacity. However, if we consider a case that the home country has a developed financial system, while the foreign country has an underdeveloped financial system, the situation will be different. Assuming that external capital capacity at home is sufficiently large, all unemployed capital in the foreign country will flow into the home country. The effect of such capital movement is just like the effect of the increase in capital endowment at home. 


\section{CONCLUSiON}

By introducing firms' demand for external finance into the HOS model, we conduct a general equilibrium analysis of financial development and study the joint effects of factor endowments and financial institution on the economy. Whether the factor endowment or the institution plays a more important role in the economy follows the law of wooden barrel: binding constraints determine the equilibrium outcome.

Our model provides a possible theoretical foundation for a political economy story of financial development. As the underdeveloped financial system prevents full employment of capital, some capital is wasted. On the one hand, financial development increases the relative output of the more financially dependent good, which reduces its relative price, and therefore reduces the return to capital and increases the wage rate. On the other hand, financial development relaxes the binding external finance constraint, and therefore reduces unemployment of capital. Both owners of unemployed capital and labor benefit from financial development, while owners of incumbent capital are worse off. Therefore, labor and owners of unemployed capital support financial development, while owners of incumbent capital oppose it.

Financial development measured by the increase in external capital capacity is treated as exogenous in this paper. Relaxing this assumption and making financial development endogenous will be an interesting topic and is left for future studies. 


\section{REFERENCES}

Antras, Pol, 2003, “Firms, Contracts, and Trade Structure," Quarterly Journal of Economics, Vol. 118, No. 4, pp. 1374-1418.

— , and Elhanan Helpman, 2004, "Global Sourcing," Journal of Political Economy, Vol. 112 , pp. 552-80.

Baldwin, Richard, 1989, "Exporting the Capital Markets: Comparative Advantage and Capital Market Imperfections," in The Convergence of International and Domestic Markets, ed. by D. Audretsch, L. Sleuwaegen, and H. Yamawaki (Amsterdam: NorthHolland Press).

Beck, Thorsten, 2002, "Financial Development and International Trade. Is There a Link?" Journal of International Economics, Vol. 57, pp.107-31.

— Market- or Bank-based System Matter?” Journal of Financial Economics, Vol. 64, pp.147-180.

Berglof, Erik, and E. von Thadden, 1994, "Short-Term versus Long-Term Interests: Capital Structure with Multiple Investors," Quarterly Journal of Economics, Vol.109, pp.1055-84.

Carlin, Wendy, and Colin Mayer, 2003, "Finance, Investment, and Growth," Journal of Financial Economics, Vol. 69, pp. 191-226.

Costinot, Arnaud 2005, "Contract Enforcement, Division of Labor, and the Pattern of Trade" (unpublished).

Davis, D., and David Weinstein, 2001, “An Account of Global Factor Trade,” American Economic Review, Vol. 91, No. 5, pp.1423-53.

— 2003, “The Factor Content of Trade," in Handbook of International Trade, Vol. I, ed. by Kwan Choi and James Harrigan (Basil: Blackwell Publishing).

Diamond, Douglas, 1991, “Debt Maturity Structure and Liquidity Risk," Quarterly Journal of Economics, Vol. 106, pp. 709-37.

Do, Quy-Toan, and Andrei Levchenko, 2004, "Trade and Financial Development" (unpublished)

Feenstra, Robert , 2004, Advanced International Trade (Princeton: Princeton University Press). 
Fisman, Raymond, and Inessa Love, 2004, "Financial Development and Growth in the Short and Long Run," NBER Working Paper 10236 (Cambridge: National Bureau of Economic Research).

Grossman, Gene, and Elhanan Helpman, 2002, "Integration Versus Outsourcing in Industry Equilibrium,” Quarterly Journal of Economics, Vol. 117, pp.85-120.

— 2005, "Outsourcing in a Global Economy," Review of Economic Studies, Vol. 72, pp.135-159.

Harrigan, James, 1997, “Technology, Factor Supplies, and International Specialization: Estimating the Neoclassical Model," American Economic Review, Vol. 87, pp. 475-94.

Hart, Oliver, and John Moore, 1998, "Default and Renegotiation: A Dynamic Model of Debt," Quarterly Journal of Economics, Vol. 113, No. 1, pp. 1-41.

Holmstrom, Bengt, and Jean Tirole, 1998, "Private and Public Supply of Liquidity," Journal of Political Economy, Vol. 106, No. 1, pp. 1-40.

Jones, Ronald, 1965, “The Structure of Simple General Equilibrium Models," Journal of Political Economy, Vol. 73, No. 6, pp. 557-72.

Kletzer, Kenneth, and Pranab Bardhan, 1987, "Credit Market and Patterns of International Trade," Journal of Development Economics, Vol. 27, pp. 57-70.

La Porta, Rafael, Florencio Lopez-de-Silanes, Andrei Shleifer, and Robert Vishny, 1997, "Legal Determinants of External Finance," Journal of Finance, Vol. 52, No. 3, pp. 1131-50.

__ 1998, "Law and Finance," Journal of Political Economy, Vol.106, No. 6, pp.1113-55.

Levchenko, Andrei, 2003, "Institution Quality and International Trade” (unpublished, MIT).

Matsuyama, Kiminori, 2005, "Credit Market Imperfection and Patterns of International Trade and Capital Flows," Journal of the European Economic Association (forthcoming).

McLaren, John, 2000, “Globalization and Vertical Structure,” American Economic Review, Vol. 90, No. 5, pp. 1239-54.

Nunn, Nathan, 2005, "Relationship-Specificity, Incomplete Contracts, and the Pattern of Trade" (unpublished).

Rajan, Raghuram, and Luigi Zingales, 1998, "Financial Development and Growth," American Economic Review, Vol. 88, No. 3, pp. 559-86. 
— , 2003, "The Great Reversals: The Politics of Financial Development in the Twentieth Century," Journal of Financial Economics, Vol. 69, pp. 5-50.

Romalis, John, 2004, "Factor Proportions and the Structure of Commodity Trade," American Economic Review, Vol. 94, No. 1, pp. 67-97.

Trefler, Daniel, 1993, “International Factor Price Differences: Leontief was Right!” Journal of Political Economy, Vol. 101, No. 6, pp. 961-87.

— 1995, "The Case of the Missing Trade and Other Mysteries," American Economic Review, Vol. 85, No. 5, pp. 1029-46. 


\section{Appendix}

\section{Proof of Proposition 1}

Totally differentiating equations (30) and (31), we obtain

$$
\begin{aligned}
& \theta_{1 w} \widehat{w}+\theta_{1 r} \widehat{r}=h_{1} \widehat{p}_{1} \\
& \theta_{2 w} \widehat{w}+\theta_{2 r} \widehat{r}=h_{2} \widehat{p}_{2}
\end{aligned}
$$

where $\widehat{w}=d w / w$ denotes the percentage change in wage rate and likewise for other variables, while $\theta_{i w}=\left(\lambda_{i}^{H} a_{i}^{1} w\right) / p_{i}, \theta_{i r}=\left(\bar{\rho}_{i}^{\frac{1}{2}} r\right) /\left[(2(1+r))^{\frac{1}{2}} p_{i}\right]$ and $h_{i}=\lambda_{i}^{H} G_{i}\left(a_{i}^{1}, 1\right)$. We can solve for the change in factor prices from equations (37) as

$$
\begin{aligned}
\widehat{w} & =\frac{\theta_{2 r} h_{1} \widehat{p}_{1}-\theta_{1 r} h_{2} \widehat{p}_{2}}{|\theta|} \text { and } \\
\widehat{r} & =\frac{\theta_{1 w} h_{2} \widehat{p}_{2}-\theta_{2 w} h_{1} \widehat{p}_{1}}{|\theta|}
\end{aligned}
$$

where $|\theta|=\theta_{1 w} \theta_{2 r}-\theta_{1 r} \theta_{2 w}$. It can be easily shown that $|\theta|>0$ if sector 1 is effectively labor intensive than sector 2 . Consider an increase in the price of good 1 which is represented by $\widehat{p}_{1}>0$ and $\widehat{p}_{2}=0$. It is immediately seen from (39) that $\widehat{w}>0$ and $\widehat{r}<0$. The effect of the increase in the price of good 2 can be similarly done. The magnification effect studied by Jones (1965) does not hold in general. $\widehat{p}_{i}$ is not a weighted average of $\widehat{w}$ and $\widehat{r}$ so we are not sure if $\widehat{p}_{i}$ lies in between $\widehat{w}$ and $\widehat{r}$. Thus, only under certain conditions will factor prices change in percentage terms by more than changes in product prices.

\section{Proof of Proposition 2}

Note that $a_{i L}=a_{i} b_{i}$ and $a_{i K}=b_{i}$. Using (22) and (25), we have

$$
\widehat{a}_{i L}=-\frac{r}{2(1+r)} \widehat{r} \text { and } \widehat{a}_{i K}=\frac{r}{2(1+r)} \widehat{r}
$$

These solutions for $\widehat{a}_{i j}(j=L, K)$ can then be substituted into equations (34) to obtain

$$
\begin{aligned}
\lambda_{1 L} \widehat{y}_{1}+\lambda_{2 L} \widehat{y}_{2} & =\widehat{L}+\frac{r}{2(1+r)} \widehat{r} \\
\lambda_{1 K} \widehat{y}_{1}+\lambda_{2 K} \widehat{y}_{2} & =\widehat{K}-\frac{r}{2(1+r)} \widehat{r}
\end{aligned}
$$

Let $|\lambda 1|$ denote the determinant of the $2 \times 2$ matrix on the left hand side of the above system. Using the fact that $\lambda_{1 j}+\lambda_{2 j}=1$, we have

$$
|\lambda 1|=\lambda_{1 L}-\lambda_{1 K}=\lambda_{2 K}-\lambda_{2 L}>0
$$


The last inequality uses the assumption that industry 1 is labor intensive, which implies that $a_{1 L} / a_{1 K}>L / K>a_{2 L} / a_{2 K}$. Consider the direct effect first and let $\widehat{r}=0$. Solving for the system of (41) and (42), we obtain the classical magnification effect that $\widehat{y}_{1}^{T}>\widehat{L}>\widehat{K}>\widehat{y}_{2}^{T}$ when $\widehat{L}-\widehat{K}>0$. If $\widehat{K}-\widehat{L}>0$, then we have $\widehat{y}_{2}>\widehat{K}>\widehat{L}>\widehat{y}_{1}$.

We then consider the feedback effect. We first derive the stability condition. Market clear condition (29) serves to define the elasticity of substitution between goods on the demand side, $\sigma_{D}$

$$
\widehat{y}_{1}-\widehat{y}_{2}=-\sigma_{D}\left(\widehat{p}_{1}-\widehat{p}_{2}\right)
$$

Subtracting (42) from (41) yields

$$
\widehat{y}_{1}-\widehat{y}_{2}=\frac{(\widehat{L}-\widehat{K})}{|\lambda 1|}+\frac{r}{|\lambda 1|(1+r)} \widehat{r}
$$

Let good 2 be the numeraire good. Using (39), (44) and (45), we have $A_{1} \widehat{r}=(\widehat{L}-\widehat{K}) /|\lambda 1|$ where

$$
A_{1}=\frac{|\lambda 1||\theta| \sigma_{D}(1+r)-r \theta_{2 w} h_{1}}{|\lambda 1|(1+r) \theta_{2 w} h_{1}}
$$

The stability condition requires that $A_{1}>0$. That is, an increase in capital endowment reduces the interest rate.

Now substituting (44) into (39), we have

$$
\widehat{r}=\frac{\theta_{2 w} h_{1}}{|\theta| \sigma_{D}}\left(\widehat{y}_{1}-\widehat{y}_{2}\right)
$$

Then substituting the above expression into equations (42), we obtain

$$
\begin{aligned}
\left(\lambda_{1 L}-\eta\right) \widehat{y}_{1}+\left(\lambda_{2 L}+\eta\right) \widehat{y}_{2} & =\widehat{L} \\
\left(\lambda_{1 K}+\eta\right) \widehat{y}_{1}+\left(\lambda_{2 K}-\eta\right) \widehat{y}_{2} & =\widehat{K}
\end{aligned}
$$

where $\eta=\left[r \theta_{2 w} h_{1}\right] /\left[2(1+r)|\theta| \sigma_{D}\right]$. Let $|\Lambda 1|$ denote the determinant of the two-by-two matrix on the left hand side of (48). The condition that $A_{1}>0$ implies that $|\Lambda 1|>0$. Solving for $\widehat{y}_{1}$ and $\widehat{y}_{2}$ gives

$$
\begin{aligned}
& \widehat{y}_{1}=\widehat{L}+\frac{\left(\lambda_{2 L}+\eta\right)(\widehat{L}-\widehat{K})}{|\Lambda 1|}>\widehat{L} \text { and } \\
& \widehat{y}_{2}=\widehat{K}-\frac{\left(\lambda_{1 K}+\eta\right)(\widehat{L}-\widehat{K})}{|\Lambda 1|}<\widehat{K}
\end{aligned}
$$

when $\widehat{L}-\widehat{K}>0$. 


\section{Proof of Proposition 3: Case 2}

Using expressions (17), (19) and (25), external capital usage per unit of production can be written as

$$
a_{i X}=\frac{1}{\lambda_{i}^{H} G_{i}\left(a_{i}^{1}, 1\right)}\left[\frac{r\left[2(1+r) \overline{\rho_{i}}\right]^{\frac{1}{2}}+\rho_{i}^{0}}{1+r}\right]
$$

Using equations (23), we obtain that $\rho_{i}^{1}+f \rho_{i}^{0}=(1+f) \rho_{i}^{*}$. Then substituting definitions of (2) and (11) into this expression, we get $\rho_{i}^{0}=\rho_{i}^{*}-\lambda_{i}^{H} B_{i} /\left[(1+f) \Delta \lambda_{i}\right]$. Using this result and the expression (21), we can rewrite (49) as

$$
a_{i X}=\frac{1}{\lambda_{i}^{H} G_{i}\left(a_{i}^{1}, 1\right)}\left[\left[2(1+r) \bar{\rho}_{i}\right]^{\frac{1}{2}}-\frac{\lambda_{i}^{H} B_{i}}{(1+f)(1+r) \Delta \lambda_{i}}\right]
$$

Note that equation (50) implies that the term inside the bracket of the right hand side of (50) is positive. Totally differentiating the above, we have

$$
\widehat{a}_{i X}=\left[\frac{\left(\frac{\overline{\rho_{i}}}{2}\right)^{\frac{1}{2}} r(1+r)^{-\frac{1}{2}}+\frac{r \lambda_{i}^{H} B_{i}}{(1+f)(1+r)^{2} \Delta \lambda_{i}}}{\left[2(1+r) \bar{\rho}_{i}\right]^{\frac{1}{2}}-\frac{\lambda_{i}^{H} B_{i}}{(1+f)(1+r) \Delta \lambda_{i}}}\right] \widehat{r}
$$

Let $\gamma_{i}$ denote the expression inside the bracket of the right hand side of equation (51), $\gamma_{i}>0$ since the denominator of the expression is positive. The expressions for $\widehat{a}_{i X}$ and $\widehat{a}_{i L}$ can then be substituted into equations (36) to obtain

$$
\begin{aligned}
\lambda_{1 L} \widehat{y}_{1}+\lambda_{2 L} \widehat{y}_{2} & =\widehat{L}+\frac{r}{2(1+r)} \widehat{r} \\
\lambda_{1 X} \widehat{y}_{1}+\lambda_{2 X} \widehat{y}_{2} & =\widehat{K^{X}}-\mu \widehat{r}
\end{aligned}
$$

where

$$
\mu=\left[\lambda_{1 X} \gamma_{1}+\lambda_{2 X} \gamma_{2}\right]>0
$$

Let $|\lambda 2|$ denote the determinant of the $2 \times 2$ matrix on the left hand side of the system (52). Note that

$$
\frac{a_{1 L}}{a_{1 K}}>\frac{a_{2 L}}{a_{2 K}} \Rightarrow \frac{a_{1 L}}{a_{1 K}}>\frac{\phi_{1} a_{2 L}}{\phi_{2} a_{2 K}} \Leftrightarrow \frac{a_{1 L}}{a_{1 X}}>\frac{a_{2 L}}{a_{2 X}}
$$

since $\phi_{1}<\phi_{2}$. Then similar to the argument for $|\lambda 1|$, we have $|\lambda 2|>0$. First, let $\widehat{w}$ and $\widehat{r}$ be zero and consider the direct effect. Solving for the system of equations (52), we obtain the magnification effect that $\widehat{y}_{2}>\widehat{K^{X}}>\widehat{L}>\widehat{y}_{1}$ when $\widehat{K^{X}}-\widehat{L}>0$. If $\widehat{L}-\widehat{K^{X}}>0$, then we have $\widehat{y}_{1}>\widehat{L}>\widehat{K^{X}}>\widehat{y}_{2}$.

We then consider the feedback effect. Substituting the expression (47) into equations (52), we obtain

$$
\begin{aligned}
\left(\lambda_{1 L}-\eta\right) \widehat{y}_{1}+\left(\lambda_{2 L}+\eta\right) \widehat{y}_{2} & =\widehat{L} \\
\left(\lambda_{1 X}+\xi\right) \widehat{y}_{1}+\left(\lambda_{2 X}-\xi\right) \widehat{y}_{2} & =\widehat{K^{X}}
\end{aligned}
$$


where $\xi=\left(\mu \theta_{2 w} h_{1}\right) /\left(|\theta| \sigma_{D}\right)$. Similar to the argument above, we have $A_{2} \widehat{r}=\left(\widehat{L}-\widehat{K^{X}}\right) /|\lambda 2|$ in this case where

$$
A_{2}=\frac{2(1+r)|\lambda 2||\theta| \sigma_{D}-\theta_{2 w} h_{1}[r+2(1+r) \mu]}{2|\lambda 2|(1+r) \theta_{2 w} h_{1}}
$$

The stability condition requires that $A_{2}>0$. Let $|\Lambda 2|$ denote the determinant of the two-by-two matrix on the left hand side of (55). The condition that $A_{2}>0$ implies $|\Lambda 2|$ to be positive. Solving for $\widehat{y}_{1}$ and $\widehat{y}_{1}$ gives $\widehat{y}_{2}>\widehat{K^{X}}>\widehat{L}>\widehat{y}_{1}$ if $\widehat{K^{X}}-\widehat{L}>0$.

\section{Analysis and Proof of Proposition 3: Case 3}

As shown in Figure 4, the $X X$ line is steeper than the $K K$ line now since $\phi_{1}>\phi_{2}$ and is inside the point $E$. The equilibrium output is determined by the intersection of the $K K$ line and the $X X$ line at point $B$. The direct effect of further financial development shifts $X X$ out to $X^{\prime} X^{\prime}$, as illustrated, and moves the equilibrium to point $B^{\prime}$. The output of industry 1 , the industry more dependent on external finance, goes up, and the output of industry 2 declines.

The feedback effect in this case differs from the previous two cases. The increase in $y_{1}$ and the decrease in $y_{2}$ reduce the relative price $p_{1}$, which increases $r$ by Proposition 1 . The increase in $r$ raises both external capital usage and the capital usage per unit of production. Thus, the feedback effect shifts in both $X X$ and $K K$ lines. The shifting in of the $K K$ line increases $y_{1}$ and reduces $y_{2}$, which strengthens the magnification effect. The shifting in of the $X X$ line, however, reduces $y_{1}$ and increases $y_{2}$, which dampens the magnification effect. Overall, $y_{1}$ will increase relative to $y_{2}$, although the composition of outputs may not change by as much, relatively, as the change in $K^{X}$. In this case, labor endowment $L$ is not fully employed. Actual labor usage is $L^{*}=a_{1} b_{1} y_{1}^{*}+a_{2} b_{2} y_{2}^{*}<L$. The unemployment of labor is equal to $L-L^{*}$. Assume that anyone in the labor force has equal probability of finding a job, which is measured by $L^{*} / L$. Thus, the expected wage of labor is given by $w L^{*} / L$ in this case. Now we turn to the mathematical proof.

Rewrite the binding capital constraint (26) and external finance constraint (28) as

$$
\begin{aligned}
& a_{1 X} y_{1}+a_{2 X} y_{2}=K^{X} \\
& a_{1 K} y_{1}+a_{2 K} y_{2}=K
\end{aligned}
$$

Totally differentiating these conditions and using (42) and (52), we obtain

$$
\begin{aligned}
& \lambda_{1 X} \widehat{y}_{1}+\lambda_{2 X} \widehat{y}_{2}=\widehat{K^{X}}-\mu \widehat{r} \\
& \lambda_{1 K} \widehat{y}_{1}+\lambda_{2 K} \widehat{y}_{2}=\widehat{K}-\frac{r}{2(1+r)} \widehat{r}
\end{aligned}
$$

Let $|\lambda 3|$ denote the determinant of the $2 \times 2$ matrix on the left hand side of the above system. Note that $a_{1 X} / a_{1 K}>a_{2 X} / a_{2 K}$ since $\phi_{1}>\phi_{2}$, which implies that $|\lambda 3|>0$. Solving for the system of equations (58) and (59) when $\widehat{r}=0$ to obtain the direct effect, we have the magnification effect that $\widehat{y}_{1}>\widehat{K^{X}}>\widehat{K}>\widehat{y}_{2}$ if $\widehat{K^{X}}-\widehat{K}>0$. 
We then consider the feedback effect. Subtracting (59) from (58) and using the result that $|\lambda 3|=\lambda_{1 X}-\lambda_{1 K}=\lambda_{2 K}-\lambda_{2 X}$, we obtain

$$
|\lambda 3|\left(\widehat{y}_{1}-\widehat{y}_{2}\right)=\left(\widehat{K^{X}}-\widehat{K}\right)+\left(-\mu+\frac{r}{2(1+r)}\right) \widehat{r}
$$

Using (39), (44), and (60), we have $A_{3} \widehat{r}=\left(\widehat{K^{X}}-\widehat{K}\right) /|\lambda 3|$ where

$$
A_{3}=\frac{2(1+r)|\lambda 3||\theta| \sigma_{D}-\theta_{2 w} h_{1}[r-2(1+r) \mu]}{2|\lambda 3|(1+r) \theta_{2 w} h_{1}}
$$

The stability condition requires that $A_{3}>0$. The equation (60) can be written as

$$
|\lambda 3|\left(\widehat{y}_{1}-\widehat{y}_{2}\right)=\left(\widehat{K^{X}}-\widehat{K}\right)+(-\xi+\eta)\left(\widehat{y}_{1}^{T}-\widehat{y}_{2}^{T}\right)
$$

Let $|\Lambda 3|=|\lambda 3|+\xi-\eta$. The condition that $A_{3}>0$ implies $|\Lambda 3|>0$. Thus, we have $\widehat{y}_{1}-\widehat{y}_{2}>0$ if $\widehat{K^{X}}-\widehat{K}>0$. 


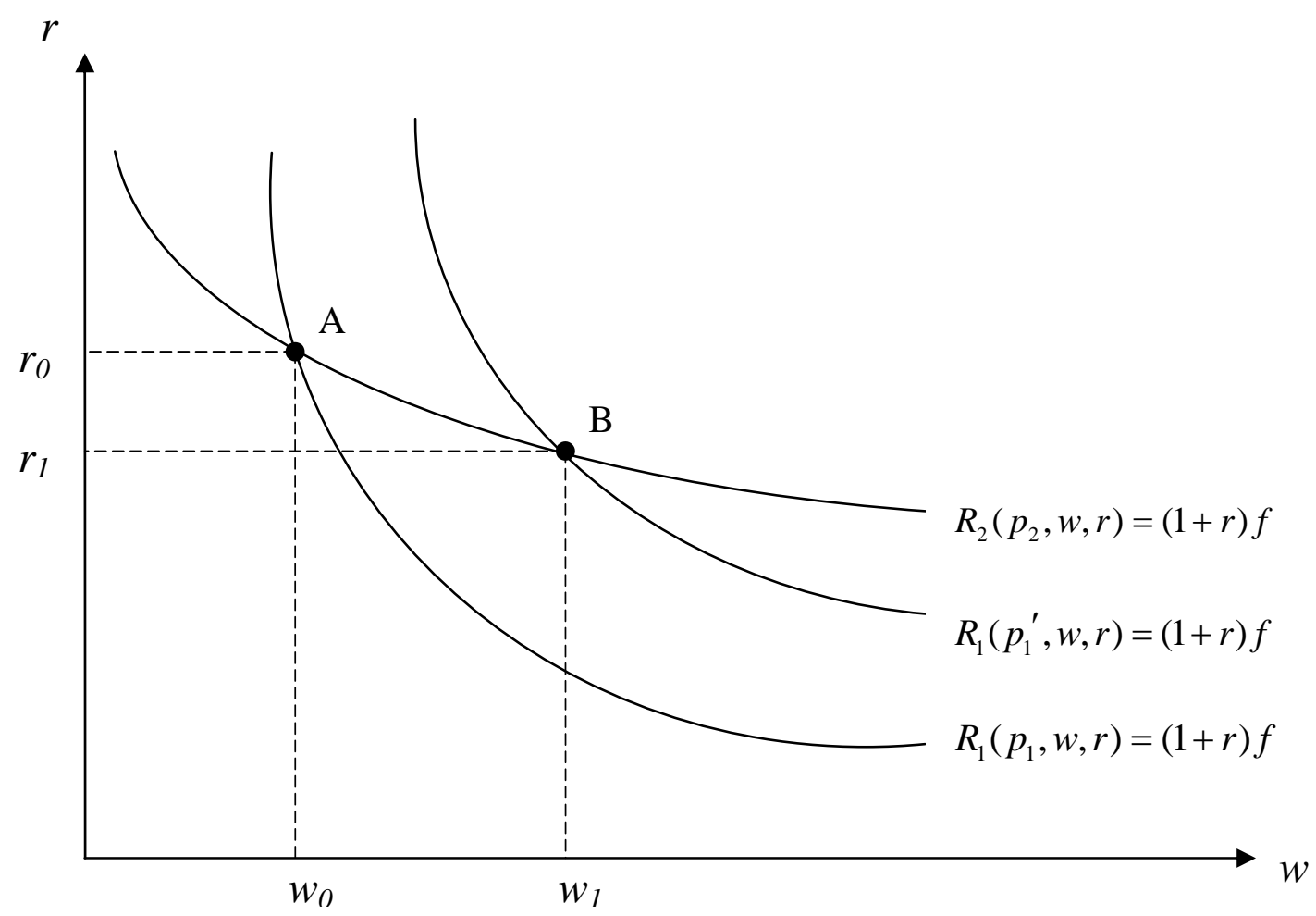

Figure 1

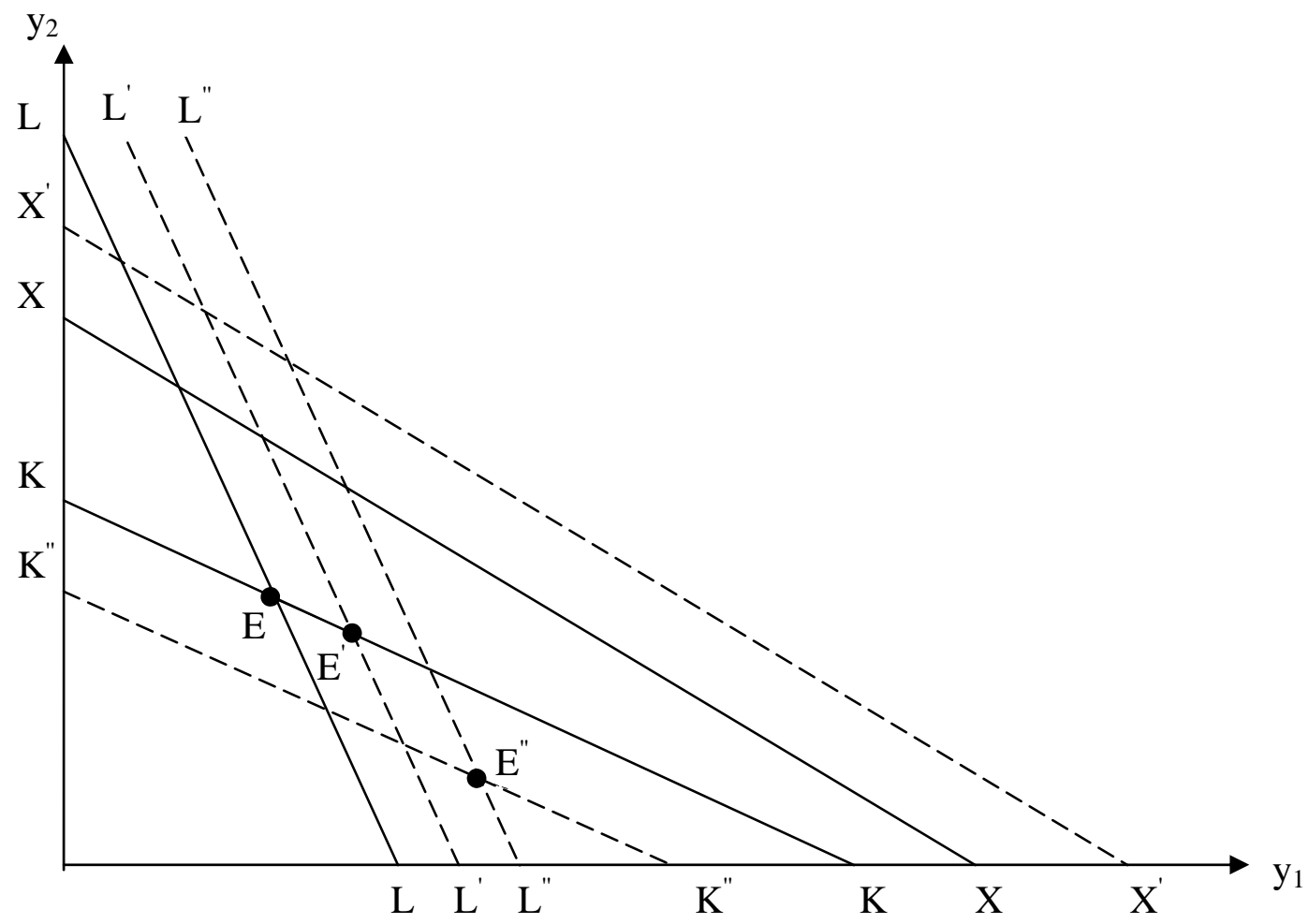

Figure 2 


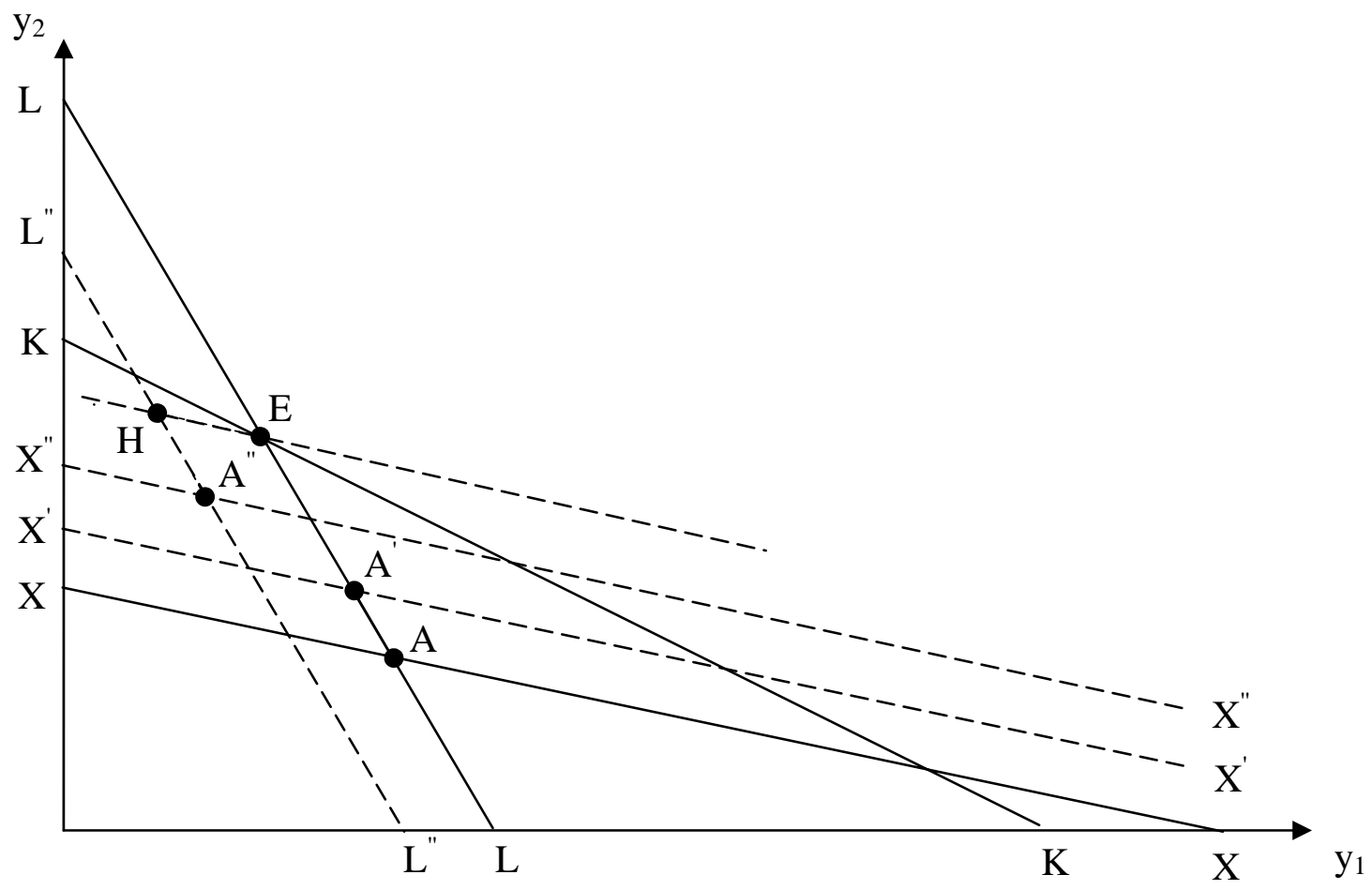

Figure 3

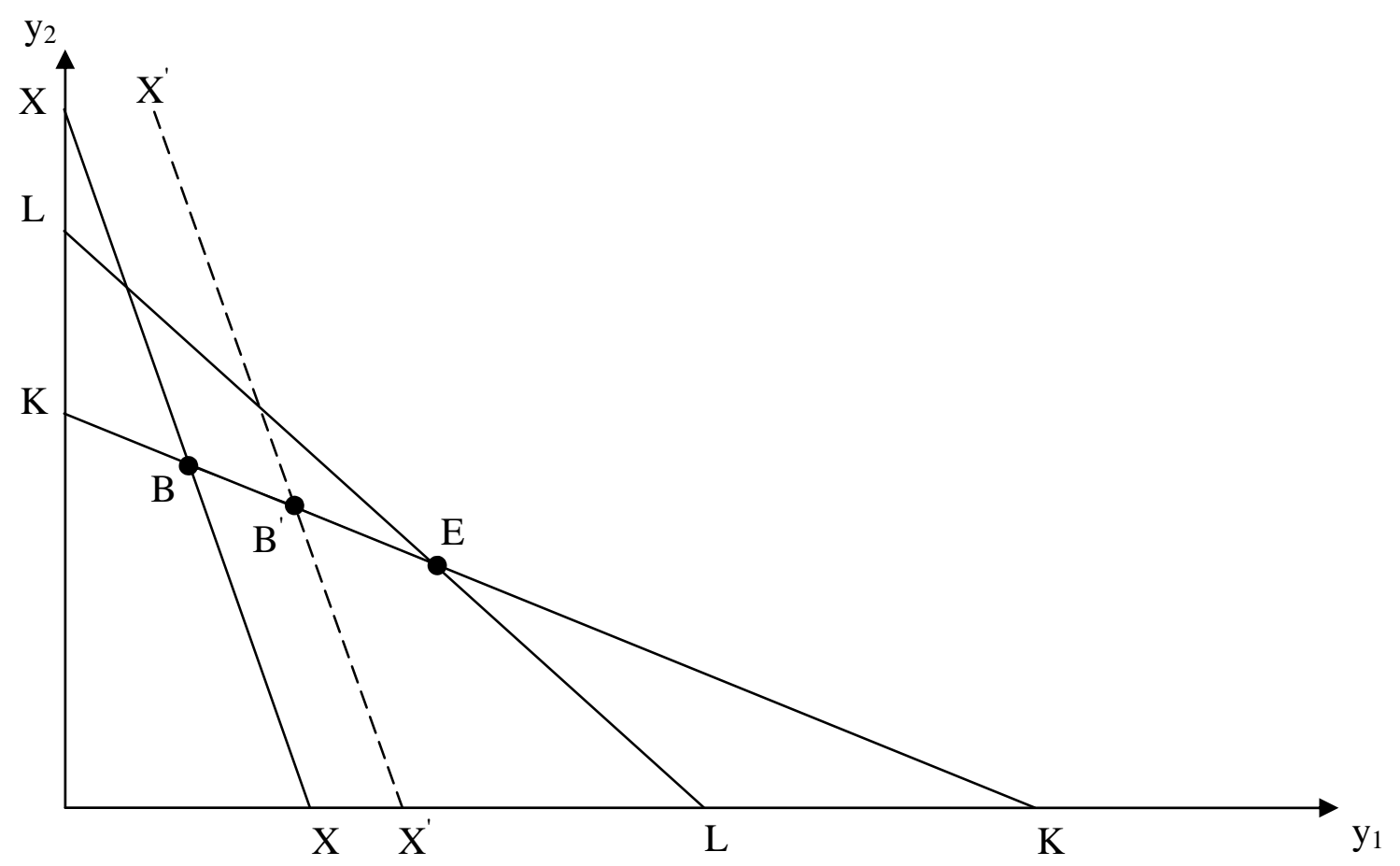

Figure 4 